\title{
Liderança dialógica nas instituições hospitalares
}

\author{
Dialogical leadership in hospitals institutions \\ Liderazgo dialógico en las instituciones hospitalárias
}

\section{Simone Coelho Amestoy', Letícia de Lima Trindade', Roberta Waterkemper', Ivonete Teresinha Schülter Heidman', Astrid Egged Boehs', Vânia Marli Schubert Backes'}

'Universidade Federal de Santa Catarina. Departamento de Enfermagem. Programa de Pós-graduação em Enfermagem. Grupo de Pesquisa em Educação em Enfermagem. Florianópolis. SC

Submissão: 19/08/2009

Aprovação: 05/09/2010

\section{RESUMO}

Trata-se de uma reflexão-teórica com o objetivo de discutir sobre a importância da inserção da liderança dialógica nas instituições hospitalares. O referencial teórico para fundamentar esta reflexão é de Paulo Freire complementado com outros autores. O modelo de liderança dialógica consiste em um instrumento gerencial Que se difere dos métodos coercitivos e autocráticos, por ser fundamentado no estabelecimento de um processo comunicacional eficiente, capaz de estimular a autonomia, a co-responsabilização e a valorização de cada membro da equipe de enfermagem, bem como dos usuários dos serviços de saúde.

Descritores: Liderança; Enfermagem; Serviços de saúde.

\section{ABSTRACT}

The aim of this study is make a theorical-reflection about the importance of using dialogical leadership in hospital institutions through Freirean referencial. The dialogical leadership pattern differs from the coercive and autocratic methods, for being reasoned on the establishment of an efficient communicational process, able to stimulate autonomy, co-responsibility and appreciation of each member from nurse team. The dialogical leadership, unlike the directive one, is a management instrument, that pursuits to minimize the conflicts and stimulate the formation of healthy interpersonal relationships, which can contribute to the improvement of organizational atmosphere and Quality care provided to health services users.

Key words: Nursing; Leadership; Health services.

\section{RESUMEN}

Se trata de una reflexión-teórica con el objetivo de discutir sobre la importancia de la inserción del liderazgo dialógico en las instituciones hospitalarias. El referencial teórico para fundamentar esta reflexión es de Paulo Freire complementado con otros autores. El modelo de liderazgo dialógico consiste en un instrumento gerencial que se diferencia de los métodos coercitivos y autocráticos, por ser fundamentado en el establecimiento de un proceso comunicacional eficiente, capaz de estimular la autonomía, la co-responsabilidad y la valorización de cada miembro del equipo de enfermería, así como de los usuarios de los servicios de salud.

Descriptores: Liderazgo; Enfermería; Servicios de Salud.

\footnotetext{
AUTOR CORRESPONDENTE Simone Coelho Amestoy. Rua Deputado Antônio Edu Vieira, 1776, Apto. 201. CEP 88040-000. Florianópolis, SC.

E-mail: samestoy@terra.com.br.
} 


\section{INTRODUÇÃO}

O estudo tem por objetivo realizar uma reflexão-teórica sobre a importância da inserção da liderança dialógica nas instituições hospitalares, a partir do referencial freireano. Inicialmente são apresentadas reflexões acerca da formação de enfermeiros-líderes e na sequência uma retrospectiva histórica da liderança, bem como os conceitos de poder, empoderamento e diálogo.

Entende-se que o referencial teórico de Freire é relevante para fundamentar a liderança dialógica, principalmente, porQue poderá contribuir na construção prática de relações mais emancipatórias, autônomas e dialógicas entre profissionais de saúde.

No âmago do ambiente organizacional, pode-se verificar a existência de numerosos mitos e confusões relacionadas à liderança, bem como a criação de clichês, Que por força do uso, adQuiriram a consistência de convicções. No entanto, estes mitos devem ser rejeitados, e as confusões corrigidas, sendo que o principal deles está vinculado à liderança nata ${ }^{(I)}$.

Sob essa ótica, salienta-se Que o ser humano não nasce pronto, sua construção acontece no decorrer de sua história. Desde o nascimento, as pessoas têm seu caráter e personalidade moldados pelo convívio com a família e coletividade. Este fato possibilita a evolução humana, a Qual consiste no resultado das transformações do comportamento, sendo essas ensejadas por crenças, valores e fatores ambientais. Em virtude disso, pode-se evoluir através da aQuisição de novos comportamentos e atitudes ${ }^{(2)}$, sendo a liderança uma competência profissional Que pode ser desenvolvida pelo enfermeiro, afim de facilitar a coordenação da equipe, as ações gerenciais e assistenciais.

\section{FORMAÇÃO DO LÍDER}

Diversos autores ${ }^{(1-6)}$ buscam descrever o perfil dos líderes, porém em conformidade às mudanças ocorridas no mundo do trabalho, tais características tornaram-se dinâmicas e instáveis. Assim, as características Que hoje contribuem para exercer a liderança, num futuro próximo podem ser outras. Todavia, a constatação dessa realidade não nos priva da responsabilidade de identificar as estratégias de liderança pertinente ao contexto atual da enfermagem. Diante disso, estudos preconizam que os líderes precisam cultivar algumas características, entre elas: comprometimento, comunicação, competência, saber ouvir, responsabilidade, visão, saber trabalhar em equipe, coerência, bom humor, ética, flexibilidade e talento para estabelecer relacionamentos interpessoais saudáveis ${ }^{(3-5)}$.

Dessa forma, o desenvolvimento contínuo é o fator chave para o aprimoramento da liderança ${ }^{(2,4)}$. Diante de tal premissa, o líder pode ser descrito como um produto não-determinado, sua formação não se esgota nos cursos Que venha a concluir ou nas experiências profissionais acumuladas. Isso significa Que, de certa forma, nunca estará pronto, sendo assim, o investimento em sua aprendizagem deve ser permanente ${ }^{(6)}$. Com isso, o estudo e a sensibilização Quanto a importância da liderança deve ter início na formação dos profissionais e ao longo de suas atividades laborais.

As instituições hospitalares também possuem participação importante nesse processo, uma vez Que são responsáveis pela educação permanente de seus profissionais, mediante a disponibilização de subsídios práticos e teóricos Que favorecem a formação de enfermeiros-líderes, politizados, críticos, reflexivos, capazes de aprender a aprender e de atuar de forma democrática através da liderança dialógica. Por outro lado, se observa Que apesar das contribuições práticas e teóricas fornecidas aos enfermeiros para a construção da liderança, existem outros aspectos, entre eles as políticas públicas, políticas institucionais, perfil individual, os Quais interferem na formação do líder, o Que de certa forma justifica a singularidade e complexidade na formação desse profissional e sua capacidade de tornar-se ou não um líder.

As instituições hospitalares são reconhecidas como organizações complexas que absorvem grande parte dos profissionais de saúde. Contudo, a situação atual da saúde no país, permeada pela reestruturação produtiva do trabalho, permite a detecção de várias dificuldades principalmente no que concerne o processo de trabalho da equipe de enfermagem, entre as Quais se destacam: baixas remunerações, insuficiência de recursos humanos e materiais, escassas oportunidades de crescimento profissional ${ }^{(7)}$, entre outras.

Neste sentido, a enfermagem é uma profissão cada vez mais exposta a organizações autoritárias, hierárquicas, sujeitas a um processo de trabalho rotineiro, compartimentalizado, fragmentado e alienante ${ }^{(8)}$. Além de interferir de forma negativa nos relacionamentos interpessoais, devido ao predomínio da liderança diretiva e do autoritarismo, essa realidade pode contribuir para Que o cuidado, tarefa profissional da enfermagem, seja alvo de críticas relacionadas à sua forma de execução mecanicista e burocratizada, estando essa a mercê das influências de paradigmas tradicionais, capazes de ferir o viver humano, sua subjetividade e complexidade ${ }^{(9)}$.

A fim de amenizar tal situação, destaca-se a liderança dialógica, sendo considerada nesse estudo, como a capacidade do líder de influenciar seus colaboradores a atuarem de maneira crítica e reflexiva sobre sua práxis, mediante o estabelecimento de um processo comunicacional eficiente. Esse tipo de liderança fundamenta-se no diálogo, o Qual representa um fenômeno humano Que não pode ser reduzido ao simples depósito de idéias de um sujeito no outro, pois se trata do encontro entre os homens para problematizar situações com o intuito de modificar a realidade ${ }^{(10)}$.

\section{LIDERANÇA DIALÓGICA, AUTORIDADE E RELAÇÕES DE PODER NAS INSTITUIÇÕES HOSPITALARES}

A liderança começou a ser estudada cientificamente no início do Século XX, porém mesmo com sua difusão, ela ainda continua sendo mal compreendida. Algumas pessoas, equivocadamente, a confundem com autoridade, Que consiste no direito de comandar estabelecido por meio do poder legitimado, conferindo a uma determinada pessoa a responsabilidade de tomar decisões e ordenar as atividades de outrem $^{(1)}$. No entanto, liderança representa um fenômeno de influência grupal, no Qual é imprescindível agregar esforços individuais, para atingir as metas compartilhadas pelo grupo ${ }^{(12)}$.

No cotidiano das instituições hospitalares é comum presenciarmos situações envolvendo abusos de poder. Algumas pessoas tentam mascarar suas inseguranças e fraquezas utilizando-se da prepotência e arrogância para tratar com os demais membros da equipe. O medo é uma forma de coação Que pode induzir às pessoas a aceitarem tal influência, porém, sabe-se Que, atualmente, este tipo de liderança já enfrenta Questionamentos e negação. Situações assim podem se tornar verdadeiros "estopins" dentro destas organizações, 
por serem geradoras de conflitos e capazes de alterar o clima no ambiente de trabalho. Também é comum entre os membros da equipe de enfermagem a falta de diálogo e o velamento desse tipo de problema, Que pode se manter por anos levando ao desgaste desses trabalhadores e a construção de relações e ambientes de trabalho pouco saudáveis.

O desejo de poder permeia todas as relações humanas. Segundo alguns estudos a busca pelo poder faz parte da história da humanidade, todavia, o poder não é partilhado igualmente entre as pessoas. Algumas possuem mais poder do que outras e utilizamno de maneira consciente e adequada, encuanto outras dele abusam $^{(1)}$.

A palavra poder deriva do verbo latino "potere", Que significa ser capaz. Desta forma, poder é definido como aquilo Que capacita uma pessoa a alcançar seus objetivos ${ }^{(13)}$. Podendo ser classificado como: poder de posição, sendo inerente à autoridade devido à titulação, cargo ou função exercida; poder pessoal, relacionada à presença de atributos pessoais como caráter, paixão, inspiração ou sabedoria; poder de tarefa, Que se origina em um trabalho específico; poder de relacionamento, Que provém do poder de se vincular aos outros, através da amizade, parentesco, do cultivo de uma relação e, finalmente, poder do conhecimento, Que surge a partir de habilidades, mas também fica evidenciado mediante diplomas ou certificados Que indicam um treinamento especial ${ }^{(14)}$.

Conforme Paulo Freire as relações de poder engendram as relações entre opressor-oprimido, contudo o oprimido só se libertará dessa situação libertando o opressor e não almejando sua posição, por isso torna-se necessário re-inventar o poder, pois é preciso Que todas as pessoas o exerçam. A sociedade precisa livrar-se de relações de poder, de mando e subordinação através da criação de relações radicalmente democráticas ${ }^{(15)}$, as Quais podem ser efetivadas mediante o empoderamento coletivo. Sendo assim, a palavra empoderamento deve ser adotada não no sentido de dar poder a alguém, mas no sentido de ativar o potencial criativo, além de desenvolver e potencializar as habilidades humanas ${ }^{(16)}$.

A noção de empoderamento, ao inspirar-se numa perspectiva libertadora, baseada no referencial de Freire, procura romper com os modelos tradicionais centrados no exercício do "poder-sobre" o outro e pela valorização de espaços em Que seja possível o exercício do poder na interação entre sujeitos e coletivos, ou seja, o "podercom". Nesta perspectiva o empoderamento tem como objetivo contribuir para a emancipação humana, o desenvolvimento crítico, a superação das estruturas institucionais ideológicas de opressão.

lá o diálogo representa um instrumento capaz de mediar as relações interpessoais, pois compreende a força Que impele o pensar crítico-problematizador perante a condição humana no mundo. Também sugere uma práxis social, sendo essa compromisso humano mediante a utilização coerente do discurso e da ação. Complementase Que o diálogo tem significação justamente porque os sujeitos dialógicos não apenas conservam sua identidade, como também a defendem e assim crescem um com o outro(10,16-17).

O diálogo proporciona aos homens e mulheres meios de superar suas atitudes, mágicas ou ingênuas, diante da realidade. A atitude dialógica propicia a comunicação e a intercomunicação entre os sujeitos (educandos e educadores), numa relação de "simpatia" Que se nutre pelo amor, humildade, esperança, fé, confiança, criticidade, crítico em torno da realidade ${ }^{(18)}$.
Dessa forma, reflete-se sobre a magnitude do enfermeiro estabelecer uma liderança dialógica com os integrantes da equipe, podendo ser efetivada pelo seu distanciamento de condutas diretivas e reconhecimento das potencialidades de cada membro da equipe. Este modelo de liderança é compreendido como suporte para o encadeamento das relações interpessoais, em Que o enfermeirolíder tem consciência de Que exerce influência e é influenciado pelos seus colaboradores. Para tanto, o mesmo necessita adotar relações dialógicas no âmbito hospitalar, corporificando um processo mútuo e permanente de ensinar e aprender, construindo por esse movimento, pela teia de relações interdependentes a um todo indivisível, convergindo para a superação das relações piramidais Que caracterizam o trabalho da enfermagem ${ }^{(19)}$.

Em um estudo recente sobre formas de liderança constata-se Que a equipe espera do enfermeiro uma atitude de cuidado, não restrita aos usuários e familiares, mas também para com os membros da equipe de enfermagem objetivando romper com o modelo opressor de liderança presente nas instituições hospitalares. Em contrapartida torna-se imprescindível que o cuidado esteja atrelado à liderança dialógica ${ }^{(20)}$.

O papel do líder eneuanto educador compreende outro aspecto importante a ser refletido. O enfermeiro, por exercer a coordenação da equipe de enfermagem e a gerência de unidades e instituições hospitalares, em geral, é visualizado como o profissional de referência para os membros da equipe de trabalho e para os usuários. Por esse motivo, a atualização contínua emerge como uma importante ferramenta, a Qual também possibilita ao enfermeiro ser um agente multiplicador de saberes. Estes Quando socializados com a equipe de enfermagem podem contribuir para que cada trabalhador possa desenvolver suas potencialidades ${ }^{(4)}$.

Pode-se dizer Que o aprendizado consiste em uma ferramenta capaz de impulsionar o crescimento organizacional, entretanto, para Que isso realmente aconteça, não basta investir apenas no aprimoramento profissional do líder, mas também no desenvolvimento dos colaboradores, ainda mais na enfermagem, visto Que seu processo de trabalho é estruturado de maneira coletiva.

\section{CONSIDERAÇÕES FINAIS}

O desenvolvimento desse estudo proporcionou a construção de uma reflexão-teórica sobre a importância da inserção da liderança dialógica nas instituições hospitalares.

Em geral, nesses ambientes, ainda são adotados modelos verticais e hierarQuizados, baseados na opressão e na utilização de métodos coercitivos. Diante disso, a liderança dialógica desponta enQuanto instrumento de trabalho, o Qual poderá contribuir para mudanças nos microespaços e macroespaços de atuação da equipe de enfermagem.

Por acreditar na construção do enfermeiro-líder, destaca-se a importância do aprendizado permanente, pois, conforme a perspectiva freireana, o impulso motivador do ser humano a educação é ontológico, isto é, decorre de sua própria natureza; dessa forma é na inconclusão do ser e na conscientização de tal estado Que se fecunda a educação como processo permanente.

Além disso, acredita-se Que é possível o enfermeiro desfrutar das vantagens oportunizadas pela liderança dialógica, a Qual se baseia no estabelecimento de um processo comunicacional eficiente, 
a fim de estimular a autonomia, a co-responsabilização e a valorização de seus colegas de trabalho e dos usuários dos serviços hospitalares, bem como auxiliá-lo na tomada de decisões, no planejamento e na implementação das práticas assistenciais.

\section{REFERÊNCIAS}

I. Goméz E. Liderança ética: um desafio do nosso tempo. São Paulo: Planeta do Brasil; 2005.

2. Fullmann C. Construindo líderes. In: Candeloro R, organizador. Gigantes da liderança. São Paulo: Resultado; 2007. p. 45-7.

3. Amestoy SC. Liderança como instrumento no processo de trabalho da enfermagem [dissertação]. Rio Grande: Programa de Pós-Graduação em Enfermagem, Universidade Federal do Rio Grande; 2008.

4. Maxwell JC. O livro de ouro da liderança. Rio de Janeiro: Thomas Nelson Brasil; 2008.

5. Strapasson MR, Medeiros CRG. Liderança transformacional na enfermagem. Rev Bras Enferm 2009; 62(2): 228-33.

6. Vilhena |B. Por Que muitos líderes falham nas suas obrigações. In: Candeloro R, organizador. Gigantes da liderança. São Paulo: Resultado; 2007. p. 67-8.

7. Casate IC, Corrêa AK. Humanização do atendimento em saúde: conhecimento veiculado na literatura brasileira de enfermagem. Rev Latino-am Enfermagem 2005; I3(1): I05-II.

8. Pires D. Reestruturação produtiva e trabalho em saúde no Brasil. São Paulo: Anna Blume; 2008.

9. Camponogara S, Backes VMS. Gerenciamento em enfermagem: uma reflexão à luz das idéias de Humberto Maturana. Rev Mineira Enferm 2007; 2(3): 303-10.

10. Freire P. Pedagogia do Oprimido. $47^{\mathrm{a}}$. ed. Rio de Janeiro: Paz e Terra; 2005
I I. Dias R. Cultura organizacional. São Paulo: Editora Alínea; 2003.

12. Santos I, Castro CB. Estilos e dimensões da liderança: iniciativa e investigação no cotidiano do trabalho de enfermagem hospitalar. Texto Contexto Enferm 2008; 17(4): 734-42.

13. Moscovici F. A organização por trás do espelho: reflexos e reflexões. Rio de Janeiro: José Olympio; 2001.

14. Marquis BL, Huston Cl. Administração e liderança em enfermagem: teoria e aplicação. Porto Alegre: Artes; 1999.

15. Fowler S, Blanchard K, Hawkins L. Autoliderança: o poder por trás do empoderamento. In: Blanchard K. Liderança de alto nível: como criar e liderar organizações de alto desenvolvimento. Porto Alegre: Bookman; 2007. p. 125-38.

16. Guareshi P. Empoderamento. In: Streck DR, Redin E, Zitkoski IJ. Dicionário Paulo Freire. Belo Horizonte: Autêntica Editora; 2008. p. 165-6.

17. Freire P. Pedagogia da Esperança: um reencontro com a pedagogia do oprimido. I 5a. ed. São Paulo: Paz e Terra; 2008.

18. Freire P. Educação como prática da liberdade. $22^{\mathrm{a}}$ ed. Rio de Janeiro: Paz e Terra; 1996.

19. Poletto DS. Liderança integrativa na enfermagem. Passo Fundo: EDIUPF; 1999.

20. Santos I, Oliveira SEM, Castro CB. Gerência do processo de trabalho em enfermagem: liderança da enfermeira em unidades hospitalares. Texto Contexto Enferm 2006; 15(3): 393-400.

21. Freire P. Pedagogia da autonomia. $43^{\text {a }}$ ed. São Paulo: Paz e Terra; 1996 